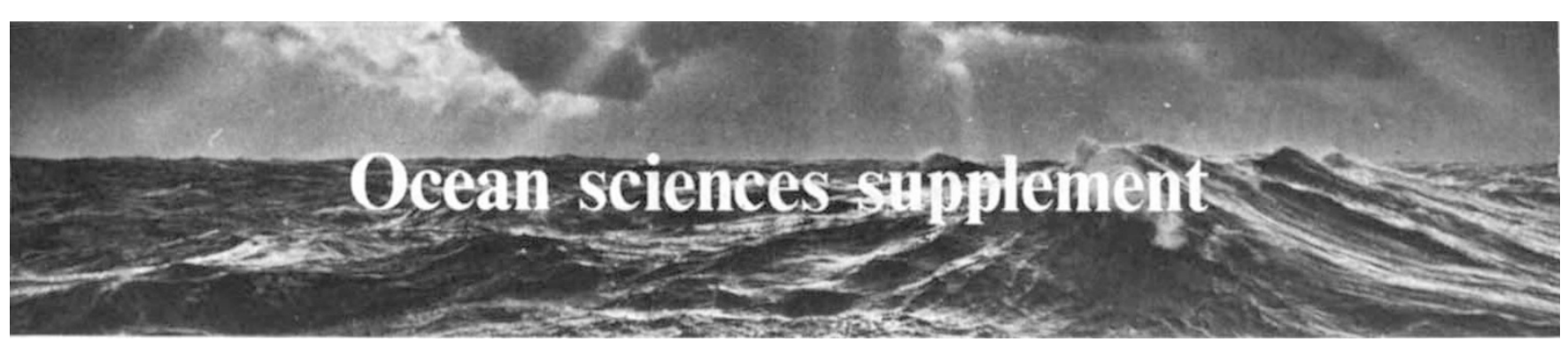

\title{
Prospects in oceanography
}

At a time when science in general has lost its magic, the science of the earth-and especially of its mysterious ocean -has been increasingly appreciated for its combination of difficulty and importance.

Plate tectonics helped a lot by providing a unifying hypothesis which could be readily grasped, and which justified the investment in earlier observations at sea, especially of the magnetic field. The deep drilling programme, now IPOD, has been a triumph of science, technology and organisation. The physical oceanographers have learned how to make direct measurements of ocean currents and discovered that the deep ocean is quite different from what they expected. There are eddies which may well be the marine equivalent of atmospheric depressions, longer lasting but smaller and slower. If they resemble atmospheric depressions to the extent of dominating the poleward transfer of heat they will be vital to our understanding of climate and climatic change. Marine biologists can now unambiguously sample macro-plankton in the deep ocean; zoogeography is becoming a quantitative science at last. Marine chemistry is now a subject in its own right.

Much of this progress has been made possible by instrumental development and skilled engineering. We have exchanged our sextants for satellites, we can dive into rift valleys, we can image the earth from space and make microphotographs at fantastic magnification. And yet we have only just started to understand the ocean; it remains dark, mysterious, enigmatic, the last great pit of ignorance on our planet. There are simple-sounding questions to which we cannot yet give satisfactory answers. An engineer designing an offshore structure may feel that we should know how surface waves are generated by the wind. A forwardlooking fisherman might expect us to know about the lifecycle of krill. A climatologist might think that we should know how much heat the Gulf Stream transports.

Oceanographers used to form a small group of rather eccentric, half-scientist, half-seaman explorers. Everybody knew that the ocean provided a support for ships, a source a food, a sink for waste and a regulator of climate, but it wasn't thought that science could help the engineers much. In those days, not so long ago, anyone making a long series of wave-observations would have been accused of wasting taxpayers' money. Now he is asked why he hadn't made many more.

There is an inevitable mismatch between the timescale of marine research and of the practical problems to which it can contribute. Environmental problems arise unexpectedly: stamping them 'immediate' cannot reduce the time it takes to make the necessary observations or get some fundamental understanding. Oceanographers must, therefore, gather as much basic information as they can: they cannot predict, any more than anybody else, what problems will come up so they must necessarily work on a variety of problems, trying to connect them into a self-supporting generality from which special cases can be sensibly studied.
The money spent on such basic research is perhaps analogous to a life assurance premium to guard against an inevitable contingency rather than to react to a particular, predictable event. It is generally desirable to pay one's assurance premium regularly and over a long period. Marine research is a bit too long-term to suit most of its customers, to use the present jargon. Perhaps it needs patrons rather than customers; in the long run, as Lord Rothschild probably appreciates, it is selective patrons who get rich.

A few problems are, however, so long-term as to be foreseeable. One concerns the disposal of high-level radioactive waste. It might be placed on, or preferably in, the sea floor; a study of the effects is clearly essential. Fortunately much relevant information and expertise is already available, thanks to an investment in basic research, so progress can be made fairly quickly, which in this context means in a decade or two.

Another long-term problem is climatic change. Man is vulnerable to relatively small changes in his environment; there is growing concern that we know so little about the mechanism of climatic change, that we cannot assess whether, or to what extent, man's activity contributes to it. If anything is clear it is that the ocean is an important component in the system-the pioneers of air-sea interaction and of ocean circulation studies weren't frittering away the taxpayers' money after all. There is a lot left to do-and it will take a long time.

Long-term, the outlook for oceanography seems good. The short-term gloom stems from a basic incompatibility between an indivisible ocean and an increasingly nationalistic world, which is offsetting what some find the main attraction, the combination of personal effort with international cooperation. Sensible legislation is clearly desirable and able scientists and lawyers are working on it. But it does not seem likely that United Nations Conferences on the Law of the Sea can do much to create the goodwill needed, whatever is finally agreed. The badly needed bridge between politics and science can only be filled by the slow process of education. It may well be that training and mutual assistance in marine science is the most valuable contribution some mature oceanographers can now make. There is a growing risk that marine research will be slowed down, not so much by lack of access but because the bright young people on whom progress depends will prefer a branch of science where freedom to make observations does not depend on unpredictable and unexplained bureaucratic decisions.

Some may argue that a check to the progress of marine research would be a iustified casualty of peace, a transient on the way to a new world order. It seems much more likely that oceanographers will be in the lead.

Henry Charnock

Professor Charnock is Director of the Institute of Oceanographic Sciences, Wormley, Surrey, UK. 